\title{
Effects Of The Third Invariant On The Fatigue Life Assessment Of Metallic Materials in Low Cycle Conditions
}

\author{
L.M. Araújo *, L. Malcher* \\ * University of Brasília, Faculty of Technology, Department of Mechanical Engineering, Campus \\ Darcy Ribeiro, Asa Norte, Brasília, DF, Brasil
}

\begin{abstract}
The importance of the third invariant $J_{3}$ for components design against ductile fracture is well known among engineers and researchers. Nevertheless, this parameter is often neglected in fatigue analysis in the low cycle regime (LCF) for the computation of stress and strain amplitudes. In this contribution, the differences between the hysteresis loops coming from traditional and $J_{3}$-based approaches of a $J_{3^{-}}$sensitive material are presented. Furthermore, the effect of $J_{3}$ on the fatigue life estimates using the Critical Plane method is analyzed. Finally, the results from this latter methodology suggest that Critical Plane approaches do not capture the influence of the loop shape in fatigue life, which indicates that energy or incremental (e.g. Damage Mechanics) techniques could be more appropriate for life assessment.
\end{abstract}
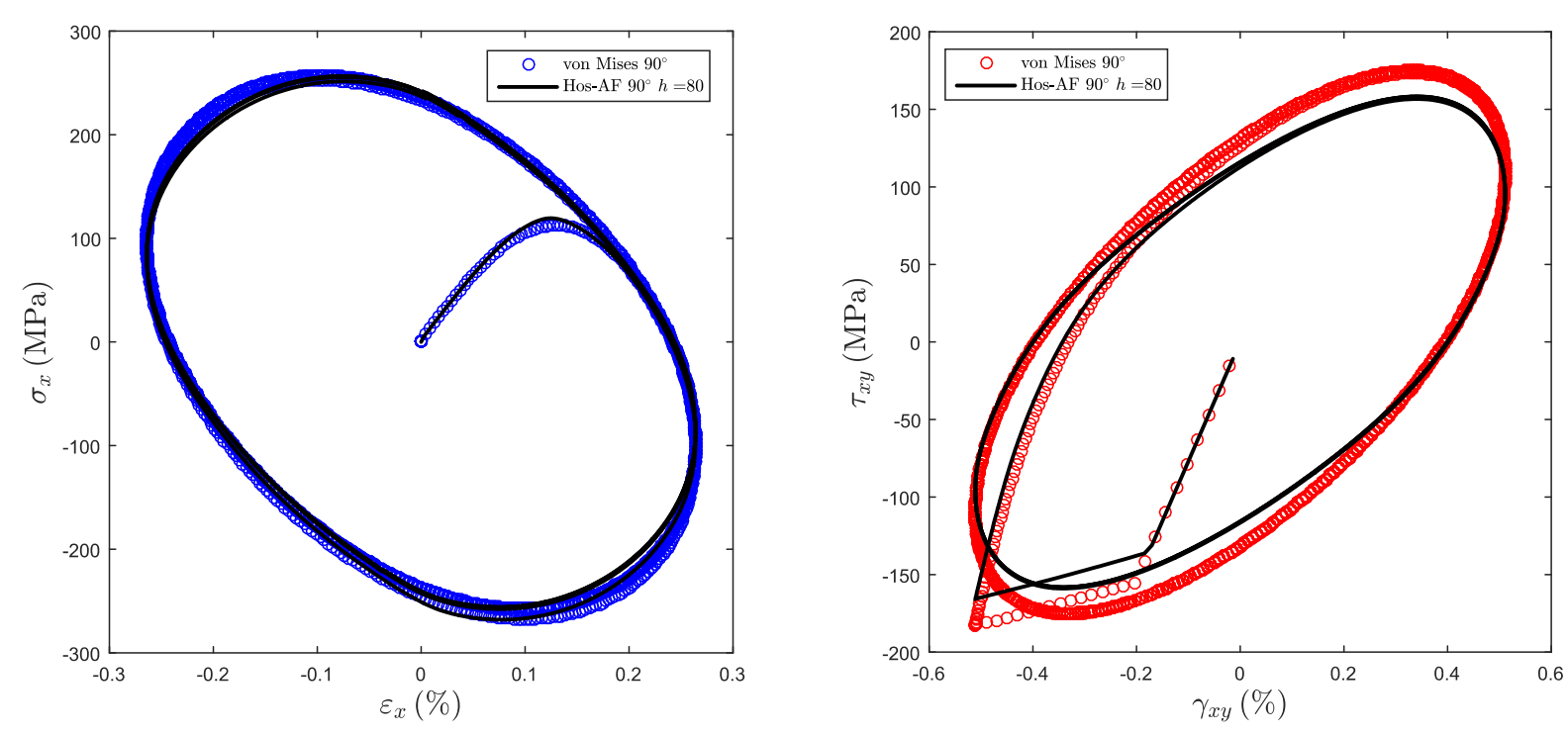

REFERENCES

Fatemi, A. \&. (1988). A Critical Plane Approach to Multiaxial Fatigue Damage Including Out-of-Phase Loading. Fatigue \& Fracture of Engineering Materials \& Structures, 149-165.

Hosford, W. F. (1972). A Generalized Isotropic Yield Criterion . Journal of Applied Mechanics, 607-609. 